\title{
Predicting the accuracy of facial affect recognition: The interaction of child maltreatment and intellectual functioning
}

\author{
Chad E. Shenk ${ }^{a,{ }^{*}}$, Frank W. Putnam ${ }^{a, b}$, and Jennie G. Nolla \\ Chad E. Shenk: chad.shenk@cchmc.org; Frank W. Putnam: frank.putnam@cchmc.org; Jennie G. Noll: \\ jennie.noll@cchmc.org \\ aDivision of Behavioral Medicine and Clinical Psychology, Cincinnati Children's Hospital Medical \\ Center, 3333 Burnet Ave., MLC 3015, Cincinnati, OH 45229, USA \\ bDepartment of Psychiatry, University of North Carolina, Chapel Hill, NC 27599, USA
}

\begin{abstract}
Previous research demonstrates that both child maltreatment and intellectual performance contribute uniquely to the accurate identification of facial affect by children and adolescents. The purpose of this study was to extend this research by examining whether child maltreatment affects the accuracy of facial recognition differently at varying levels of intellectual functioning. A sample of maltreated $(n=50)$ and nonmaltreated $(n=56)$ adolescent females, 14 to 19 years of age, was recruited to participate in this study. Participants completed demographic and studyrelated questionnaires and interviews to control for potential psychological and psychiatric confounds such as symptoms of posttraumatic stress disorder, negative affect, and difficulties in emotion regulation. Participants also completed an experimental paradigm that recorded responses to facial affect displays starting in a neutral expression and changing into a full expression of one of six emotions: happiness, sadness, anger, disgust, fear, or surprise. Hierarchical multiple regression assessed the incremental advantage of evaluating the interaction between child maltreatment and intellectual functioning. Results indicated that the interaction term accounted for a significant amount of additional variance in the accurate identification of facial affect after controlling for relevant covariates and main effects. Specifically, maltreated females with lower levels of intellectual functioning were least accurate in identifying facial affect displays, whereas those with higher levels of intellectual functioning performed as well as nonmaltreated females. These results suggest that maltreatment and intellectual functioning interact to predict the recognition of facial affect, with potential long-term consequences for the interpersonal functioning of maltreated females.
\end{abstract}

\section{Keywords}

Affect recognition; Child maltreatment; Intellectual functioning; Accuracy; Adolescent; Female

\section{Introduction}

Facial expressions provide a rich source of information that viewers can use to generate hypotheses about the current emotional state of another person, leading to contextually relevant behavioral responses that have important individual and interpersonal functions. For instance, certain discrete facial movements can inform the viewer that another person is experiencing sadness. Once these facial movements are detected and appropriately

(C) 2012 Elsevier Inc. All rights reserved.

Corresponding author. Fax: +1 5136360756 . 
categorized as an expression of sadness, the viewer can then provide an empathic verbal response to achieve individual goals, such as identifying the conditions leading to this emotional state, or interpersonal goals, such as providing general emotional support to a friend or facilitating individual emotion regulation in a child. Such responses can also inform the person expressing the emotion on how to communicate sadness in a way that provides access to important individual and social contingencies, such as empathy. However, different expressions of affect communicate different interpersonal needs, and accurately recognizing a host of different affective expressions can increase the probability of discriminating which behavioral response to provide in a given context. Thus, accurately recognizing facial expressions of affect is a key developmental task for children and adolescents with significant implications for individual and interpersonal functioning.

Facial affect recognition is facilitated by several neurological processes. Discrete movements in facial muscles are detected visually (Ekman \& Friesen, 1978) and are processed by both global and specific neural systems associated with affect (Sabatini et al., 2009), including the amygdala (Monk et al., 2003; Phillips et al., 2004), flexible fusiform area (van de Riet, Grezes, \& de Gelder, 2009), inferior parietal cortex (Adolphs, Damasio, Tranel, \& Damasio, 1996), and orbitofrontal and occipital cortices (Sabatinelli et al., 2011). Activation in these neural systems leads to further information processing in key frontal areas responsible for higher order processes and tasks, such as language and categorization (Sprengelmeyer, Rausch, Eysel, \& Przuntek, 1998). Activating frontal cortices provides access to encoded labels for emotion previously paired with similarly expressed movements in facial muscles. This process allows the individual to put socially acceptable emotion labels to visually processed information in order to increase the probability of correctly categorizing the expressed facial display.

Prior learning also plays a critical role in how facial affect displays are classified into distinct emotion categories (Pollak \& Kistler, 2002). Like many behaviors, the strength of accurately recognizing facial affect depends largely on the frequency and intensity of exposure to different expressions (Beale \& Keil, 1995; Keyes, 2012; Pollak, 2003). Parents can play a particularly important role in shaping affect recognition by providing repeated occasions where specific emotion labels corresponding to current affective expressions are given to a child. In contrast to parents who do not provide such opportunities (Krause, Mendelson, \& Lynch, 2003; Sullivan, Carmody, \& Lewis, 2010), parents who label and model affective expressions have children who are more competent emotionally (Denham, Mitchell-Copeland, Strandberg, Auerbach, \& Blair, 1997; Fruzzetti \& Shenk, 2008), setting them on a trajectory for improved emotional (Shipman et al., 2007), interpersonal (Eisenberg et al., 2001), and behavioral (Eisenberg et al., 2005) outcomes. As perceptual acuities, neurological systems, and learning experiences are continually refined and shaped across development, the ability to recognize emotions more accurately increases over time, providing important advantages for optimal development.

Research on the effects of child maltreatment, including physical abuse, sexual abuse, and neglect, has highlighted the importance of how certain environmental events can disrupt key developmental processes, including the accurate recognition of facial affect (Pollak, 2008). Child maltreatment affects nearly 700,000 children each year in the United States (US Department of Health \& Human Services, 2011) and is associated with a number of adverse developmental (Shields \& Cicchetti, 2001), physical (Bentley \& Widom, 2009), and psychological (Fergusson, Boden, \& Horwood, 2008) health outcomes. There is a growing literature linking instances of child maltreatment to alterations in neurological structures, including the visual cortex (Tomoda, Navalta, Polcari, Sadato, \& Teicher, 2009), orbitofrontal cortex (Hanson et al., 2010), amygdala (Maheu et al., 2010; Mehta et al., 2009), prefrontal cortex (Carrion et al., 2009), and cerebellar volumes (De Bellis \& 
Kuchibhatla, 2006). This research suggests that child maltreatment may significantly affect brain-behavior functioning in the domains specifically needed for facial affect recognition (McCrory, De Brito, \& Viding, 2010; Pollak et al., 2010). Child maltreatment is also linked to general and specific deficits in affect recognition when compared with nonmaltreated controls (Pears \& Fisher, 2005; Pollak, Klorman, Thatcher, \& Cicchetti, 2001). Moreover, there are a number of learning experiences unique to maltreated children that can affect the accuracy of facial affect recognition. Neglected children have greater difficulty in discriminating between distinct affective expressions (Pollak, Cicchetti, Hornung, \& Reed, 2000), which may be due to living in an environment that deprives these children of learning how to recognize and label different affective expressions. Physically abused children can more accurately detect displays of anger, even with less sensory information, when compared with nonmaltreated controls (Pollak \& Sinha, 2002). This is believed to result from more frequent and intense exposure to anger displays in these homes (Pollak, Messner, Kistler, \& Cohn, 2009) while serving to increase prediction of potential physical aggression in the future. Finally, maltreated children, including those who experienced sexual abuse, were no less accurate in recognizing facial affect but displayed significantly faster reaction times when compared with nonmaltreated controls (Masten et al., 2008). This suggests that maltreated children may become sensitized to the recognition of specific negative emotions that serve a potentially adaptive function in their current environment. Thus, child maltreatment may affect both the biological systems and learning processes central to the accurate recognition of facial affect.

Intellectual functioning plays a key role in accurately identifying expressions of affect (Anderson \& Miller, 1998), most likely because it measures fluid and crystallized abilities that are shaped by both neurological development and prior learning experiences (Horn \& Noll, 1997). Refinement of fluid and crystallized abilities corresponds with a developmental trend of improved affect recognition from childhood (Szekely et al., 2011), through adolescence (Gao \& Maurer, 2009), and into adulthood (Horning, Cornwell, \& Davis, in press). Thus, variations in the acquisition of fluid and crystallized abilities may have a differential impact on one's ability to recognize affect in others. Deficits in intellectual functioning are consistently noted for maltreated children (Carrey, Butter, Persinger, \& Bialik, 1995; De Bellis, Hooper, Spratt, \& Woolley, 2009), which can extend throughout the life course (Noll et al., 2010) and potentially limit one's ability to recognize affect across developmental stages. However, much of the previous research on affect recognition in maltreated children views intellectual functioning as a nuisance variable requiring statistical or methodological control to detect the main effects of child maltreatment despite evidence that intellectual functioning plays an incremental role over neglectful parenting when modeling emotional knowledge (Sullivan et al., 2010). This approach prevents an opportunity to examine whether the relationship between child maltreatment and affect recognition varies across different levels of intellectual functioning. This could identify intellectual ability as a protective or risk factor for maltreated children, yielding important implications for prevention and intervention programs via direct targeting of fluid and crystallized abilities.

The developmental traumatology model (De Bellis et al., 1999) specifies that child maltreatment affects developing biological mechanisms that alter the performance and structure of neurological systems regulating developmental and behavioral outcomes. Extending this model to the domain of affect recognition, maltreatment status and intellectual functioning are regarded as independent variables, whereas accurately detecting and discriminating between different emotions is a key developmental outcome. An important area of research in developmental traumatology is to assess the interactions between independent variables, such as child maltreatment and intellectual functioning, to understand the impact of these variables on child development more completely. Directly 
examining the interaction between child maltreatment and intellectual functioning can identify whether the effects of child maltreatment on affect recognition are constant across varying levels of intellectual ability.

The primary research hypothesis for the current study stated that child maltreatment and intellectual functioning will interact to predict the accuracy of facial affect recognition. Given the extant literature showing the unique effects of both child maltreatment and intellectual functioning as main effect variables, it was specified that the interaction term will explain a significant amount of additional variance in the accurate recognition of facial affect when compared with a prior model estimating child maltreatment and intellectual functioning as single indicator variables. To test this hypothesis, adolescents experiencing multiple forms of substantiated child maltreatment, sexual abuse, physical abuse, and neglect, were recruited along with a nonmaltreated comparison group. An assessment of overall accuracy in response to the facial expressions of six primary emotions-happiness, sadness, fear, disgust, surprise, and anger-was undertaken. Common psychological and psychiatric outcomes of maltreatment, such as symptoms of posttraumatic stress disorder (PTSD), difficulties in emotion regulation, and negative affect, were assessed for use as potential covariates in statistical modeling because this has been noted as a significant limitation of research on affect recognition with maltreated samples (Hart \& Rubia, 2012; Saigh, Yasik, Oberfield, Halamandaris, \& Bremner, 2006).

\section{Methods}

\section{Participants}

Adolescent females $(N=106), 14$ to 19 years of age, participated in this study. An exclusively female sample was recruited because females are more likely to be abused overall and are more likely to experience sexual abuse specifically (Sedlak et al., 2010), an underrepresented subpopulation in the existing literature. Moreover, older adolescents were recruited given results suggesting that the effect of trauma, such as child maltreatment, may be mitigated during later stages of development (Maheu et al., 2010; Pine et al., 2005; Twamley, Hami, \& Stein, 2004). Thus, the current sample provides important information on the relationship of multiple forms of maltreatment on affect recognition at an important developmental stage. Substantiation of child maltreatment was determined by a Child Protective Services (CPS) agency investigation of physical neglect or contact physical or sexual abuse. Of the 50 maltreated participants, $48 \%$ experienced one instance of sexual abuse, $46 \%$ experienced one instance of physical abuse, and $16 \%$ experienced one instance of physical neglect. A total of $10 \%$ of the maltreated females experienced multiple abuse types. Comparison females $(n=56)$ were recruited from a primary care outpatient clinic servicing the general medical complaints of at-risk adolescent females located within a pediatric hospital. This outpatient clinic was chosen as a recruitment site over alternative venues because it serves a population with a similar demographic profile as those in the maltreated group (see Table 1). The aim was to recruit a comparison group similar to the maltreated group in demographics but different in terms of maltreatment status. Thus, comparison females were screened and excluded from the current study if they had a substantiated case of maltreatment prior to study entry. A dummy-coded variable, child maltreatment, was created to distinguish between participants with a substantiated case of maltreatment (child maltreatment $=1$ ) from those without (child maltreatment $=0$ ). The mean age of the total sample was 16.97 years $(S D=1.19), 58 \%$ of the adolescents were from single-caregiver homes, the median family income level was $\$ 20,000$ to $\$ 29,000$, and the sample was 42\% Caucasian, 52\% African American, 1\% Hispanic, and 5\% multiracial. Demographic information is presented by group membership in Table 1. 


\section{Procedure}

All procedures were approved by the local institutional review board prior to beginning the study. Participants responding to recruitment efforts were provided with initial information about the study and scheduled for a laboratory assessment. On arrival, complete information about the study and study procedures was provided to all adolescent participants and to their nonabusing caregivers when the adolescents were under 18 years of age $(n=79)$. Once questions and concerns about participation were addressed, signed consent and child assent (when applicable) were obtained. Participants then completed demographic and trauma interviews, self-report questionnaires, an intellectual assessment, and a facial affect recognition task.

\section{Measures}

Difficulties in emotion regulation scale-The Difficulties in Emotion Regulation Scale (DERS; Gratz \& Roemer, 2004) is a 36-item questionnaire assessing several aspects of emotion regulation: nonacceptance of emotions, difficulties with engaging in goaloriented behavior, difficulties with impulse control, lack of emotional awareness, limited access to emotion regulation strategies, and lack of emotional clarity. The DERS has excellent internal consistency $(a=.93)$ and strong construct validity with other measures of emotion regulation (Gratz \& Roemer, 2004). Internal consistency for the DERS in the current sample is $a=.93$. In the current study, the total score on the DERS was used, representing an individual's overall difficulty in regulating emotions, with higher scores reflecting greater difficulties.

Positive and negative affect schedule-The Positive and Negative Affect Schedule (PANAS; Watson, Clark, \& Tellegen, 1988) is a 20-item self-report questionnaire assessing current positive and negative affective states as well as the subjective intensity of these states. Reliability of the PANAS in a nonclinical sample indicates strong internal consistency in both the positive $(a=.89)$ and negative $(a=.85)$ affect scales along with good concurrent validity with measures of depression and anxiety (Crawford \& Henry, 2004). Intensity ratings for the positive and negative affect scales of the PANAS were collected to assess the impact of current affective state on accuracy of affect recognition. Internal consistencies of the PANAS positive and negative affect scales in the current sample were $a=.83$ and $a=.72$, respectively.

Comprehensive Trauma Interview-The Comprehensive Trauma Interview (CTI; Barnes, Noll, Putnam, \& Trickett, 2009) is a semistructured interview assessing a wide variety of information following an instance of child maltreatment and has demonstrated good interrater reliability with information collected from CPS investigations $(\kappa \mathrm{s}=.70-.87)$. Based on a structured clinical interview (Davidson, Smith, \& Kudler, 1989), the CTI has a specific section devoted to the assessment of PTSD symptoms consistent with the Diagnostic and Statistical Manual of Mental Disorders-IV-Text Revision (American Psychiatric Association, 2000). Examples of questions asked include "Have you ever had painful images, memories, or thoughts of what happened?"; "Have you ever avoided doing things or getting into situations that reminded you of what happened?"; and "Have you ever been jumpy, on edge, or easily startled because of what happened?" Responses to questions about PTSD symptoms are coded $(0=n o, 1=y e s)$, and a summary score of all responses is then calculated to reflect cumulative levels of PTSD symptoms. Reliability of the items used to derive the summary score for PTSD symptoms in the current sample was $a=.89$.

Woodcock-Johnson-III tests of cognitive abilities-The Brief Intellectual Ability (BIA) scale was used to estimate the intellectual functioning of all participants by obtaining an index of overall IQ. The BIA is derived from three subtests on the Woodcock-Johnson- 
III Tests of Cognitive Abilities (WJ-III; Woodcock, McGrew, \& Mather, 2001): (a) Verbal Comprehension, which measures acquired knowledge; (b) Concept Formation, which measures fluid reasoning; and (c) Visual Matching, which measures visual and cognitive efficiency. Median reliabilities for these three subtests range from .89 to .94 for children and adolescents. Estimates of IQ obtained using the BIA have good concurrent validity ( $r \mathrm{~s}=$. 60-.71) with other intellectual assessments used with children and adolescents (McGrew \& Woodcock, 2001).

Experimental paradigm-The Dynamic Affect Recognition and Evaluation (DARE; Porges, Cohn, Bal, \& Lamb, 2007) task was used to assess the accuracy of facial affect recognition in this study. The DARE uses a standardized presentation of facial stimuli taken from the Cohn-Kanade Action Unit-Coded Facial Expression Database (Kanade, Cohn, \& Tian, 2000), where cross-validation tests exhibit good concordance $(\kappa \mathrm{s}=.63-.87)$ with the established Facial Affect Coding System (Cohn, Zlochower, Lien, \& Kanade, 1999). A modified version of the facial stimuli developed by Cohn and colleagues (1999) was used in the current study, where video images of still facial expressions taken from a single person were morphed into a single video that started with a neutral facial expression and transitioned into an expression of one of six basic emotions: happiness, sadness, fear, surprise, disgust, or anger (see Fig. 1). Video length varied (range $=15.73-33.80 \mathrm{~s}$ ) depending on the number of frames in the original image sequence, but it did not vary by type of emotion.

During Phase 1, participants completed a task orientation phase where one example from each of the six emotion categories was presented in a randomly determined order to familiarize participants with how the DARE task displays expressions of facial affect. Once an example fully transitioned from a neutral face to the full affective expression, a screen appeared listing each of the six emotion categories. The DARE then highlighted the correct emotion label corresponding to the previous facial affect display. During Phase 2, participants completed a second task orientation phase so that each participant could rehearse and master the behavioral responses required to complete the DARE successfully. A second set of six emotions, one from each category, was presented in a randomly determined order. However, during Phase 2 participants were instructed to press a key on a keyboard as soon as they recognized the emotion being expressed. Pressing the key halted the display of facial affect, and the screen listing the six emotion labels was then presented to participants. Once this screen was presented, participants were instructed to select the emotion label that corresponded to the previously viewed affective display. During Phases 1 and 2, participants were provided with verbal feedback on their performance in order to promote rehearsal and accurate responding. Phase 3 was the formal evaluation of facial affect recognition, and none of the facial displays used during Phases 1 and 2 were used during Phase 3. Phase 3 followed the same format as Phase 2 except that verbal feedback was not provided to participants. Phase 3 consisted of randomly determined displays of facial affect, where each emotion is expressed six different times by six different people of varying genders and racial backgrounds. This yielded a total of 36 facial affect displays ( 6 presentations _ 6 emotions), with accuracy $(0=n o, 1=y e s)$ and latency (number of seconds from start of video until key press or end of video) data obtained from each participant. Accuracy ratings across the 36 responses were then aggregated for subsequent data analysis.

\section{Results}

Preliminary data analysis was conducted to identify potential covariates for subsequent statistical modeling. Covariates were identified based on demographic and study-related variables that differed significantly between maltreated and nonmaltreated groups or that had a significant relationship with the primary outcome, that is, overall accuracy in detecting 
facial affect displays. Chi-square and multivariate analysis of variance (MANOVA) tests assessed differences between maltreatment and comparison groups on key demographic and study-related variables. Chi-square tests indicated that there were no significant group differences on race, family income, and family environment. The omnibus MANOVA yielded a significant main effect for group membership, with univariate tests indicating that the maltreated group had significantly more PTSD symptoms, greater DERS scores, and lower BIA scores (see Table 1). A trend toward significance was found for age, $F(1,100)=$ $3.13, p=.08, \eta 2=.03$. A zero-order correlation matrix assessed the relationship between demographic and study-related variables and overall accuracy on the DARE. As seen in Table 2, PTSD symptoms, DERS scores, BIA scores, and child maltreatment all were significantly associated with the accuracy of facial affect recognition. A trend for significance was observed for the relationship between family income and accuracy $(r=.18$, $p=.06$ ). Of note, maltreatment status was not related to the latency of affect recognition, and latency was not related to how accurate participants were on the DARE. Based on the results of the preliminary data analysis, age, family income, PTSD symptoms, and DERS scores were included as covariates in the primary statistical modeling of accuracy scores.

Hierarchical multiple regression was used to establish the incremental value of assessing the interaction between child maltreatment and BIA scores when predicting accuracy scores from the DARE. The regression model consisted of three blocks and assessed the additional variance explained with the estimation of each added block. Age, family income, PTSD symptoms, and DERS scores were entered simultaneously as covariates at Block 1. This block resulted in a significant overall model, $F(4,95)=3.89, p<.01$, accounting for $14 \%$ of the variance in accuracy scores. Child maltreatment status and BIA scores were entered as main effects at Block 2 along with each variable entered at Block 1. Results produced a significant overall model, $F(6,93)=4.88, p<.001$, accounting for an additional $10 \%$ of the variance in accuracy scores. The child maltreatment by BIA scores interaction term was created by multiplying the mean-centered values of each individual variable and then was entered at Block 3 along with all variables entered at Block 2. Results again indicated an overall effect for the model, $F(7,92)=6.01, p<.001$, explaining a significant amount of additional variance in accuracy scores (7\%). The child maltreatment by BIA scores interaction term significantly predicted accuracy scores even after controlling for covariates and main effects $(b=.15, p<.01)$. Fig. 2 graphically displays this interaction and indicates that maltreated children with lower BIA scores were least accurate on the DARE. Fully tabulated results of the hierarchical regression model are presented in Table 3.

Post hoc analyses were conducted to explore (a) whether child maltreatment was associated with less accurate responses to specific emotions, (b) which WJ-III subtests were associated with overall accuracy, and (c) whether accuracy scores were disproportionately related to one or more maltreatment subtypes. Results indicated that the maltreatment group was significantly less accurate in recognizing fear, $F(1,104)=4.22, p<.05, \eta 2=.04$, with a marginal effect noted for anger, $F(1,104)=3.67, p=.06, \eta 2=.03$ (see Fig. 3). Zero-order correlations indicated that the BIA subtests-Verbal Comprehension $(r=.36, p<.001)$, Concept Formation $(r=.39, p<.001)$, and Visual Matching $(r=.27, p<.01)$-each had moderate and significant relationships with overall accuracy. The subtests with significant relationships with the recognition of fear were Verbal Comprehension $(r=.36, p<.001)$ and Concept Formation $(r=.35, p<.001)$. Examination of maltreatment subtypes indicated that there were no significant effects for any individual type of abuse or neglect on the accuracy of affect recognition $(p s=.15-.70)$. 


\section{Discussion and conclusions}

Results from the current study support general findings in the existing research literature on facial affect recognition while contributing substantive new findings. First, maltreatment status was significantly related to the accuracy of affect recognition, most notably in response to expressions of fear. This finding supports previous research identifying deficits in the accurate recognition of facial affect, especially fear, in maltreated samples (Pollak et al., 2000). Moreover, the relationship between child maltreatment and affect recognition did not vary by maltreatment subtype, physical abuse, sexual abuse, or neglect. This suggests that the experience of maltreatment itself, not one particular category of abuse, is related to deficits in affect recognition. Second, this study found a significant relationship between intellectual functioning and facial affect recognition. This finding supports existing research assessing the incremental contributions of current intellectual functioning to affect recognition in maltreated samples (Sullivan et al., 2010). The current study also makes a novel contribution to this literature by examining whether child maltreatment differentially affects accuracy in facial affect recognition at varying levels of intellectual functioning. Results indicated that, on average, nonmaltreated females were successful in accurately recognizing facial affect irrespective of their level of intellectual functioning. However, maltreated females with lower intellectual functioning were least accurate in recognizing facial affect. This places them at considerable risk for missing important interpersonal cues with family members, friends, or even their own children that can have significant individual and interpersonal consequences. Conversely, maltreated females with higher levels of intellectual functioning performed as accurately as their nonmaltreated counterparts. In this case, improved intellectual functioning served a protective function for these maltreated females when presented with the task of accurately recognizing the affective displays of another person. The importance of this overall finding is enhanced when consideration is given to the statistical control of several important demographic, psychiatric, and psychological factors associated with child maltreatment, intellectual functioning, and affect recognition.

Results from this study also contrast with other published studies examining the relationship between child maltreatment and facial affect recognition. Previous research has shown that maltreated children viewing facial affect displays had significantly shorter reaction times when compared with nonmaltreated controls, particularly in response to fear expressions, while maintaining comparable levels of accuracy (Masten et al., 2008). Superior recognition of negative emotions has also been reported for maltreated children (Leist \& Dadds, 2009; Pollak \& Sinha, 2002). The current study did not find any significant differences between the maltreated and comparison groups on reaction times. Moreover, the current study observed significant differences in the accurate recognition of facial affect, where maltreated children were significantly less accurate than nonmaltreated comparisons. One explanation for these discrepancies could be the samples used across the current and previous studies. For instance, Masten and colleagues' (2008) study recruited a younger sample $(N=46)$, where the maltreated children experienced considerable overlap across maltreatment subtypes and the number of abuse incidents and where the majority of children were still in protective services custody. These prior and current experiences may place more demands on maltreated children to more quickly recognize facial affect, specifically fear, in order to ensure their own or another person's safety. The current study used a sample that was older, where the overlap in abuse types was relatively small and where the adolescents were living in stable care giving environments. Thus, the current study may indicate deficits that emerge in older adolescents and young adults outside of protective services involvement (Noll et al., 2010). Future research that more closely examines the impact of how recent the abuse occurred and the total number of abuse incidents will greatly advance this line of research. Moreover, clinical samples of older adolescents with a history of maltreatment may include 
further moderating variables that influence affect recognition in ways that are different from nonclinical samples. For instance, Leist and Dadds's (2009) study evaluated the accuracy of affect recognition in a sample of adolescents $(N=23)$ receiving mental health and substance abuse treatment. These clinical issues were also positively related to affect recognition and may contribute shared variance on how child maltreatment affects one's ability to identify emotions more accurately under these conditions. The current study recruited a nonclinical sample and attempted to control for comorbid psychopathology in order to gain additional insight into the mutual contributions of child maltreatment and intellectual functioning. Thus, sampling characteristics will be an important methodological aspect to consider when conducting future research on affect recognition with maltreated samples.

There are several limitations to this study that should be considered while interpreting the results. First, the sample consists entirely of female adolescents. An exclusive female sample was chosen because they are most likely to experience child maltreatment, specifically sexual abuse (Sedlak et al., 2010). While advancing the literature in several ways, the results have implications for this subpopulation of adolescents only and cannot generalize to male adolescents. Further research on how the interaction of child maltreatment and intellectual functioning is related to the accuracy of affect recognition in males is needed. Second, substantiated cases of child maltreatment were used to determine maltreatment status. Although using substantiated cases offers several methodological advantages in the assessment of child maltreatment (Hardt \& Rutter, 2004; Stoltenborgh, van Ijzendoorn, Euser, \& Bakermans-Kranenburg, 2011), this method cannot detect "true" cases of abuse or neglect that go unreported to CPS, and so findings from this study generalize only to substantiated cases. Finally, the age range of the sample is relatively small and pertains to middle to late adolescence. The focus of this study was to provide an assessment of how child maltreatment and intellectual functioning interact to predict the accuracy of facial affect recognition given developmental differences in previous research (Maheu et al., 2010; Pine et al., 2005; Twamley et al., 2004). Results of this study add to this literature but do not generalize to younger children or adolescents.

So what can be done to improve the accuracy of facial affect recognition, especially for maltreated females with lower intellectual functioning? Prevention of child maltreatment is the first and most obvious answer given its association with a wide range of health outcomes in addition to affect recognition. Universal prevention programs, such as home visitation for at-risk first-time mothers, are an effective method for providing the tools needed to reduce parenting distress and avoid engagement in punitive or neglectful parenting (Ammerman et al., 2011). Moreover, it is clear that the types of learning environments to which children are exposed plays a key role in facilitating the accurate recognition of facial affect (Pollak et al., 2009). Thus, providing maltreated female adolescents with lower intellectual functioning with frequent opportunities to observe affective expressions in a supportive and instructive manner may enhance their ability to recognize emotions more accurately (Guralnick, 2005). Deficits in verbal comprehension and conceptual learning were the aspects of intellectual functioning most strongly associated with errors in accuracy in this study. Expanding the verbal lexicon of maltreated females, in conjunction with frequent exposure to affective expressions, may be one way to improve their ability to recognize facial affect (Golan \& Baron-Cohen, 2006). Although there is debate on this issue (Farah, Wilson, Drain, \& Tanaka, 1998; Gauthier \& Tarr, 1997), providing a more rich affective learning environment across child development may help to refine perceptual and neural systems involved in affect recognition (Pollak and Kistler, 2002), enhancing both crystallized and fluid reasoning abilities associated with the formulation of emotional concepts and categorization. Finally, clinical interventions for maltreated females may be enhanced by direct targeting of affect recognition. This can improve the recognition of affect and expand the lexicon of available emotional labels while improving the ability to regulate emotions and function 
interpersonally. Improvements in the accuracy of affect recognition in this population have the potential of benefiting individual and interpersonal goals currently and in the future.

\section{Acknowledgments}

This project was supported by an Institutional Clinical and Translational Science Award (NIH/NCRR Grant \#: 1UL1RR026314), the National Institute on Child Health and Human Development (Noll: R01HD052533), and the National Institute of Diabetes and Digestive and Kidney Diseases (Powers: T32DK063929).

\section{References}

Adolphs R, Damasio H, Tranel D, Damasio AR. Cortical systems for the recognition of emotion in facial expressions. Journal of Neuroscience. 1996; 16:7678-7687. [PubMed: 8922424]

American Psychiatric Association. Diagnostic and statisical manual of mental disorders-IV - Text revision (DSM-IV - TR). Washington, DC: Author; 2000.

Ammerman RT, Putnam FW, Stevens J, Bosse NR, Short JA, Bodley AL, et al. An open trial of inhome CBT for depressed mothers in home visitation. Maternal and Child Health Journal. 2011; 15:1333-1341. [PubMed: 20936338]

Anderson M, Miller KL. Modularity, mental retardation, and speed of processing. Developmental Science. 1998; 1:239-245.

Barnes JE, Noll JG, Putnam FW, Trickett PK. Sexual and physical revictimization among victims of severe childhood sexual abuse. Child Abuse \& Neglect. 2009; 33:412-420. [PubMed: 19596434]

Beale JM, Keil FC. Categorical effects in the perception of faces. Cognition. 1995; 57:217-239. [PubMed: 8556842]

Bentley T, Widom CS. A 30-year follow-up of the effects of child abuse and neglect on obesity in adulthood. Obesity. 2009; 17:1900-1905. [PubMed: 19478789]

Carrey NJ, Butter HJ, Persinger MA, Bialik RJ. Physiological and cognitive correlates of child abuse. Journal of the American Academy of Child and Adolescent Psychiatry. 1995; 34:1067-1075. [PubMed: 7545147]

Carrion VG, Weems CF, Watson C, Eliez S, Menon V, Reiss AL. Converging evidence for abnormalities of the prefrontal cortex and evaluation of midsagittal structures in pediatric posttraumatic stress disorder: An MRI study. Psychiatry Research. 2009; 172:226-234. [PubMed: 19349151]

Cohn JF, Zlochower AJ, Lien J, Kanade T. Automated face analysis by feature point tracking has high concurrent validity with manual FACS coding. Psychophysiology. 1999; 36:35-43. [PubMed: 10098378]

Crawford JR, Henry JD. The Positive and Negative Affect Schedule (PANAS): Construct validity, measurement properties, and normative data in a large non-clinical sample. British Journal of Clinical Psychology. 2004; 43:245-265. [PubMed: 15333231]

Davidson J, Smith R, Kudler H. Validity and reliability of the DSM-III criteria for posttraumatic stress disorder: Experience with a structured interview. Journal of Nervous and Mental Disease. 1989; 177:336-341. [PubMed: 2723621]

De Bellis MD, Baum AS, Birmaher B, Keshavan MS, Eccard CH, Boring AM, et al. Developmental traumatology. I: Biological stress systems. Biological Psychiatry. 1999; 45:1259-1270. [PubMed: 10349032]

De Bellis MD, Hooper SR, Spratt EG, Woolley DP. Neuropsychological findings in childhood neglect and their relationships to pediatric PTSD. Journal of the International Neuropsychological Society. 2009; 15:868-878. [PubMed: 19703321]

De Bellis MD, Kuchibhatla M. Cerebellar volumes in pediatric maltreatment-related posttraumatic stress disorder. Biological Psychiatry. 2006; 60:697-703. [PubMed: 16934769]

Denham SA, Mitchell-Copeland J, Strandberg K, Auerbach S, Blair K. Parental contributions to preschoolers' emotional competence. Direct and indirect effects. Motivation \& Emotion. 1997; 21:65-86. 
Eisenberg N, Gershoff ET, Fabes RA, Shepard SA, Cumberland AJ, Losoya SH, et al. Mother's emotional expressivity and children's behavior problems and social competence. Mediation through children's regulation. Developmental Psychology. 2001; 37:475-490. [PubMed: 11444484]

Eisenberg N, Zhou Q, Spinrad TL, Valiente C, Fabes RA, Liew J. Relations among positive parenting, children's effortful control, and externalizing problems: A three-wave longitudinal study. Child Development. 2005; 76:1055-1071. [PubMed: 16150002]

Ekman, P.; Friesen, WV. Facial action coding system: A technique for the measurement of facial movement. Palo Alto, CA: Consulting Psychologists Press; 1978.

Farah MJ, Wilson KD, Drain M, Tanaka JN. What is "special” about face perception? Psychological Review. 1998; 105:482-498. [PubMed: 9697428]

Fergusson DM, Boden JM, Horwood LJ. Exposure to childhood sexual and physical abuse and adjustment in early adulthood. Child Abuse \& Neglect. 2008; 32:607-619. [PubMed: 18565580]

Fruzzetti AE, Shenk C. Fostering validating responses in families. Social Work in Mental Health. 2008; 6:215-227.

Gao X, Maurer D. Influence of intensity on children's sensitivity to happy, sad, and fearful facial expressions. Journal of Experimental Child Psychology. 2009; 102:503-521. [PubMed: 19124135]

Gauthier I, Tarr MJ. Becoming a "Greeble" expert: Exploring mechanisms for face recognition. Vision Research. 1997; 37:1673-1682. [PubMed: 9231232]

Golan O, Baron-Cohen S. Systemizing empathy: Teaching adults with Asperger syndrome or highfunctioning autism to recognize complex emotions using interactive multimedia. Development and Psychopathology. 2006; 18:591-617. [PubMed: 16600069]

Gratz KL, Roemer L. Multidimensional assessment of emotion regulation and dysregulation: Development, factor structure, and initial validation of the difficulties in emotion regulation scale. Journal of Psychopathology \& Behavioral Assessment. 2004; 26:41-54.

Guralnick MJ. Early intervention for children with intellectual disabilities: Current knowledge and future prospects. Journal of Applied Research in Intellectual Disabilities. 2005; 18:313-324.

Hanson JL, Chung MK, Avants BB, Shirtcliff EA, Gee JC, Davidson RJ, et al. Early stress is associated with alterations in the orbitofrontal cortex: A tensor-based morphometry investigation of brain structure and behavioral risk. Journal of Neuroscience. 2010; 30:7466-7472. [PubMed: 20519521]

Hardt J, Rutter M. Validity of adult retrospective reports of adverse childhood experiences: Review of the evidence. Journal of Child Psychology \& Psychiatry. 2004; 45:260-273. [PubMed: 14982240]

Hart H, Rubia K. Neuroimaging of child abuse: A critical review. Frontiers in Human Neuroscience. 2012; 6:52. [PubMed: 22457645]

Horn, JL.; Noll, J. Human cognitive capabilities: Gf-Gc theory. In: Flanagan, DP.; Genshaft, JL.; Harrison, PL., editors. Contemporary intellectual assessment: Theories, tests, and issues. New York: Guilford; 1997. p. 53-91.

Horning, SM.; Cornwell, RE.; Davis, HP. The recognition of facial expressions: An investigation of the influence of age and cognition. Neuropsychology, Development, and Cognition B: Aging, Neuropsychology, and Cognition. in presshttp://dx.doi.org/10.1080/13825585.2011.645011

Kanade, T.; Cohn, JF.; Tian, Y. Comprehensive database for facial expression analysis. Paper presented at the proceedings of the fourth IEEE international conference on automatic face and gesture recognition; Grenoble, France. 2000.

Keyes H. Categorical perception effects for facial identity in robustly represented familiar and selffaces: The role of configural and featural information. Quarterly Journal of Experimental Psychology. 2012; 65:760-772.

Krause ED, Mendelson T, Lynch TR. Childhood emotional invalidation and adult psychological distress: The mediating role of emotional inhibition. Child Abuse \& Neglect. 2003; 27:199-213. [PubMed: 12615094]

Leist T, Dadds MR. Adolescents' ability to read different emotional faces relates to their history of maltreatment and type of psychopathology. Clinical Child Psychology and Psychiatry. 2009; 14:237-250. [PubMed: 19293321] 
Maheu FS, Dozier M, Guyer AE, Mandell D, Peloso E, Poeth K, et al. A preliminary study of medial temporal lobe function in youths with a history of caregiver deprivation and emotional neglect. Cognitive, Affective, \& Behavioral Neuroscience. 2010; 10:34-49.

Masten CL, Guyer AE, Hodgdon HB, McClure EB, Charney DS, Ernst M, et al. Recognition of facial emotions among maltreated children with high rates of post-traumatic stress disorder. Child Abuse \& Neglect. 2008; 32:139-153. [PubMed: 18155144]

McCrory E, De Brito SA, Viding E. Research review: The neurobiology and genetics of maltreatment and adversity. Journal of Child Psychology and Psychiatry. 2010; 51:1079-1095. [PubMed: 20546078]

McGrew, KS.; Woodcock, RW. Woodcock-Johnson-III technical manual. Itasca, IL: Riverside; 2001.

Mehta MA, Golembo NI, Nosarti C, Colvert E, Mota A, Williams SC, et al. Amygdala, hippocampal, and corpus callosum size following severe early institutional deprivation: The English and Romanian Adoptees Study pilot. Journal of Child Psychology and Psychiatry. 2009; 50:943-951. [PubMed: 19457047]

Monk CS, Grillon C, Baas JM, McClure EB, Nelson EE, Zarahn E, et al. A neuroimaging method for the study of threat in adolescents. Developmental Psychobiology. 2003; 43:359-366. [PubMed: 15027419]

Noll JG, Shenk CE, Yeh MT, Ji J, Putnam FW, Trickett PK. Receptive language and educational attainment for sexually abused females. Pediatrics. 2010; 126:e615-e622. [PubMed: 20696731]

Pears KC, Fisher PA. Emotion understanding and theory of mind among maltreated children in foster care: Evidence of deficits. Development and Psychopathology. 2005; 17:47-65. [PubMed: 15971759]

Phillips ML, Williams LM, Heining M, Herba CM, Russell T, Andrew C, et al. Differential neural responses to overt and covert presentations of facial expressions of fear and disgust. NeuroImage. 2004; 21:1484-1496. [PubMed: 15050573]

Pine DS, Mogg K, Bradley BP, Montgomery L, Monk CS, McClure E, et al. Attention bias to threat in maltreated children: Implications for vulnerability to stress-related psychopathology. American Journal of Psychiatry. 2005; 162:291-296. [PubMed: 15677593]

Pollak SD. Experience-dependent affective learning and risk for psychopathology in children. Annals of the New York Academy of Sciences. 2003; 1008:102-111. [PubMed: 14998876]

Pollak SD. Mechanisms linking early experience and the emergence of emotions: Illustrations from the study of maltreated children. Current Directions in Psychological Science. 2008; 17:370-375. [PubMed: 21701602]

Pollak SD, Cicchetti D, Hornung K, Reed A. Recognizing emotion in faces: Developmental effects of child abuse and neglect. Developmental Psychology. 2000; 36:679-688. [PubMed: 10976606]

Pollak SD, Kistler DJ. Early experience is associated with the development of categorical representations for facial expressions of emotion. Proceedings of the National Academy of Sciences of the United States of America. 2002; 99:9072-9076. [PubMed: 12072570]

Pollak SD, Klorman R, Thatcher JE, Cicchetti D. P3b reflects maltreated children's reactions to facial displays of emotion. Psychophysiology. 2001; 38:267-274. [PubMed: 11347872]

Pollak SD, Messner M, Kistler DJ, Cohn JF. Development of perceptual expertise in emotion recognition. Cognition. 2009; 110:242-247. [PubMed: 19059585]

Pollak SD, Nelson CA, Schlaak MF, Roeber BJ, Wewerka SS, Wiik KL, et al. Neurodevelopmental effects of early deprivation in postinstitutionalized children. Child Development. 2010; 81:224236. [PubMed: 20331664]

Pollak SD, Sinha P. Effects of early experience on children's recognition of facial displays of emotion. Developmental Psychology. 2002; 38:784-791. [PubMed: 12220055]

Porges, SW.; Cohn, JF.; Bal, E.; Lamb, D. The dynamic affect recognition evaluation (DARE) software. Chicago: The Brain-Body Center, University of Illinois-Chicago; 2007.

Sabatinelli D, Fortune EE, Li Q, Siddiqui A, Krafft C, Oliver WT, et al. Emotional perception: Metaanalyses of face and natural scene processing. NeuroImage. 2011; 54:2524-2533. [PubMed: 20951215] 
Sabatini E, Della Penna S, Franciotti R, Ferretti A, Zoccolotti P, et al. Brain structures activated by overt and covert emotional visual stimuli. Brain Research Bulletin. 2009; 79:258-264. [PubMed: 19480985]

Saigh PA, Yasik AE, Oberfield RA, Halamandaris PV, Bremner JD. The intellectual performance of traumatized children and adolescents with or without posttraumatic stress disorder. Journal of Abnormal Psychology. 2006; 115:332-340. [PubMed: 16737397]

Sedlak, AJ.; Mettenburg, J.; Basena, M.; Petta, I.; McPherson, K.; Greene, A., et al. Fourth national incidence study of child abuse and neglect (NIS-4): Report to congress. Washington, DC: US Department of Health and Human Services; 2010.

Shields A, Cicchetti D. Parental maltreatment and emotion dysregulation as risk factors for bullying and victimization in middle childhood. Journal of Clinical Child Psychology. 2001; 30:349-363. [PubMed: 11501252]

Shipman KL, Schneider R, Fitzgerald MM, Sims C, Swisher L, Edwards A. Maternal emotion socialization in maltreating and non-maltreating families: Implications for children's emotion regulation. Social Development. 2007; 16:268-285.

Sprengelmeyer R, Rausch M, Eysel UT, Przuntek H. Neural structures associated with recognition of facial expressions of basic emotions. Proceedings of the Royal Society B: Biological Sciences. 1998; 265:1927-1931.

Stoltenborgh M, van Ijzendoorn MH, Euser EM, Bakermans-Kranenburg MJ. A global perspective on child sexual abuse: Meta-analysis of prevalence around the world. Child Maltreatment. 2011; 16:79-101. [PubMed: 21511741]

Sullivan MW, Carmody DP, Lewis M. How neglect and punitiveness influence emotion knowledge. Child Psychiatry \& Human Development. 2010; 41:285-298. [PubMed: 20099078]

Szekely E, Tiemeier H, Arends LR, Jaddoe VW, Hofman A, Verhulst FC, et al. Recognition of facial expressions of emotions by 3-year-olds. Emotion. 2011; 11:425-435. [PubMed: 21500910]

Tomoda A, Navalta CP, Polcari A, Sadato N, Teicher MH. Childhood sexual abuse is associated with reduced gray matter volume in visual cortex of young women. Biological Psychiatry. 2009; 66:642-648. [PubMed: 19560122]

Twamley EW, Hami S, Stein MB. Neuropsychological function in college students with and without posttraumatic stress disorder. Psychiatry Research. 2004; 126:265-274. [PubMed: 15157752]

US Department of Health and Human Services. Child maltreatment, 2010. Washington, DC: Author; 2011.

van de Riet WA, Grezes J, de Gelder B. Specific and common brain regions involved in the perception of faces and bodies and the representation of their emotional expressions. Social Neuroscience. 2009; 4:101-120. [PubMed: 19255912]

Watson D, Clark LA, Tellegen A. Development and validation of brief measures of positive and negative affect: The PANAS scales. Journal of Personality \& Social Psychology. 1988; 54:10631070. [PubMed: 3397865]

Woodcock, RW.; McGrew, KS.; Mather, N. Woodcock-Johnson III tests of cognitive abilities. Itasca, IL: Riverside; 2001. 

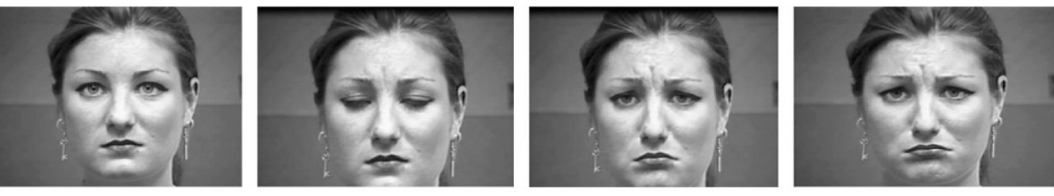

Fig. 1.

Sample images of the facial expression of sadness in the Dynamic Affect Recognition Evaluation (@Jeffrey Cohn). 


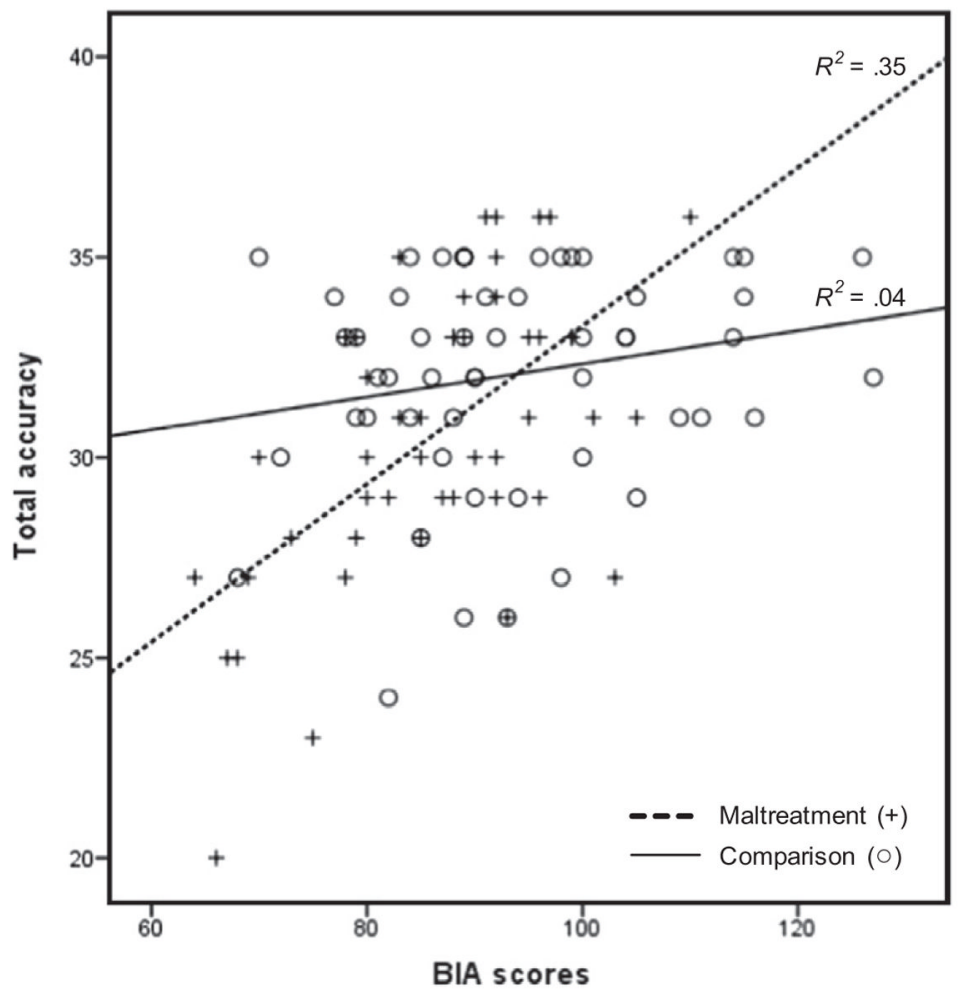

Fig. 2.

Interaction between child maltreatment and Brief Intellectual Assessment (BIA) scores in predicting the total accuracy of facial affect recognition. 


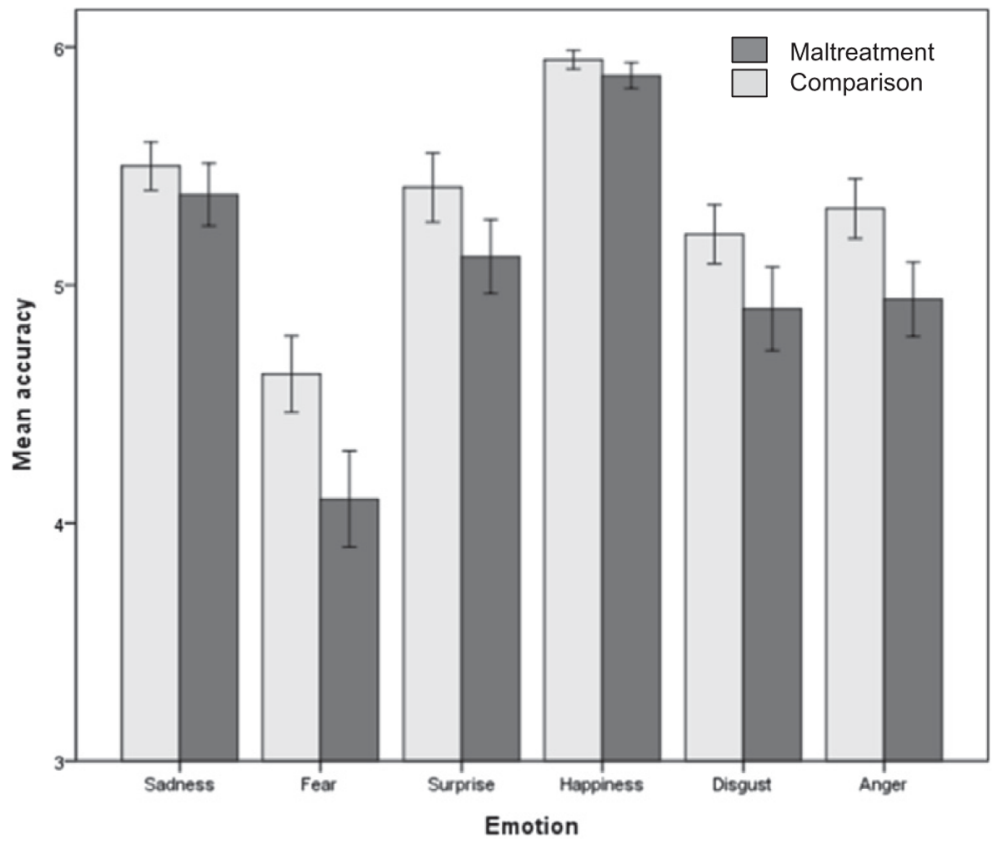

Fig. 3.

Mean differences ( \pm 1 standard error) between maltreated and nonmaltreated groups on accuracy of recognizing individual emotions. 


\section{Table 1}

Demographic information for maltreated and comparison groups.

\begin{tabular}{|c|c|c|}
\hline Variable & Maltreated $(n=50)[M(S D)$ or $n(\%)]$ & Comparison $(n=56)[M(S D)$ or $n(\%)]$ \\
\hline Age & $16.75(1.11)$ & $17.17(1.23)^{* t}$ \\
\hline \multicolumn{3}{|l|}{ Race } \\
\hline African American & $24(23 \%)$ & $31(29 \%)$ \\
\hline Caucasian & $24(23 \%)$ & $20(19 \%)$ \\
\hline Hispanic & $0(0 \%)$ & $1(1 \%)$ \\
\hline Multiracial & $2(2 \%)$ & $4(4 \%)$ \\
\hline \multicolumn{3}{|l|}{ Family income } \\
\hline$<\$ 10,000$ & $14(13 \%)$ & $13(13 \%)$ \\
\hline$\$ 10,000-\$ 19,000$ & $8(8 \%)$ & $6(6 \%)$ \\
\hline$\$ 20,000-\$ 29,000$ & $8(8 \%)$ & $9(9 \%)$ \\
\hline$\$ 30,000-\$ 39,000$ & $5(5 \%)$ & $10(10 \%)$ \\
\hline$>\$ 40,000$ & $14(13 \%)$ & $17(16 \%)$ \\
\hline \multicolumn{3}{|l|}{ Family environment } \\
\hline Single-caregiver home & $26(26 \%)$ & $31(31 \%)$ \\
\hline Dual-caregiver home & $14(14 \%)$ & $23(20 \%)$ \\
\hline Other & $6(6 \%)$ & $2(2 \%)$ \\
\hline BIA & 86.50 (10.76) & $93.56(13.52)^{*}$ \\
\hline \multicolumn{3}{|l|}{ PANAS } \\
\hline Positive Affect & $27.96(7.93)$ & $30.16(8.39)$ \\
\hline Negative Affect & $13.46(4.05)$ & $12.46(3.31)$ \\
\hline PTSD symptoms & $8.28(4.90)$ & $3.75(3.97)^{* *}$ \\
\hline DERS & $91.10(23.70)$ & $78.16(21.14) *$ \\
\hline
\end{tabular}

Note. BIA, Brief Intellectual Assessment via Woodcock-Johnson Test of Cognitive Abilities-III; PANAS, Positive and Negative Affect Schedule; PTSD, posttraumatic stress disorder; DERS, Difficulties in Emotion Regulation Scale.

$t_{p} \leq 10$.

* $p \leq .01$.

** $p \leq .001$. 


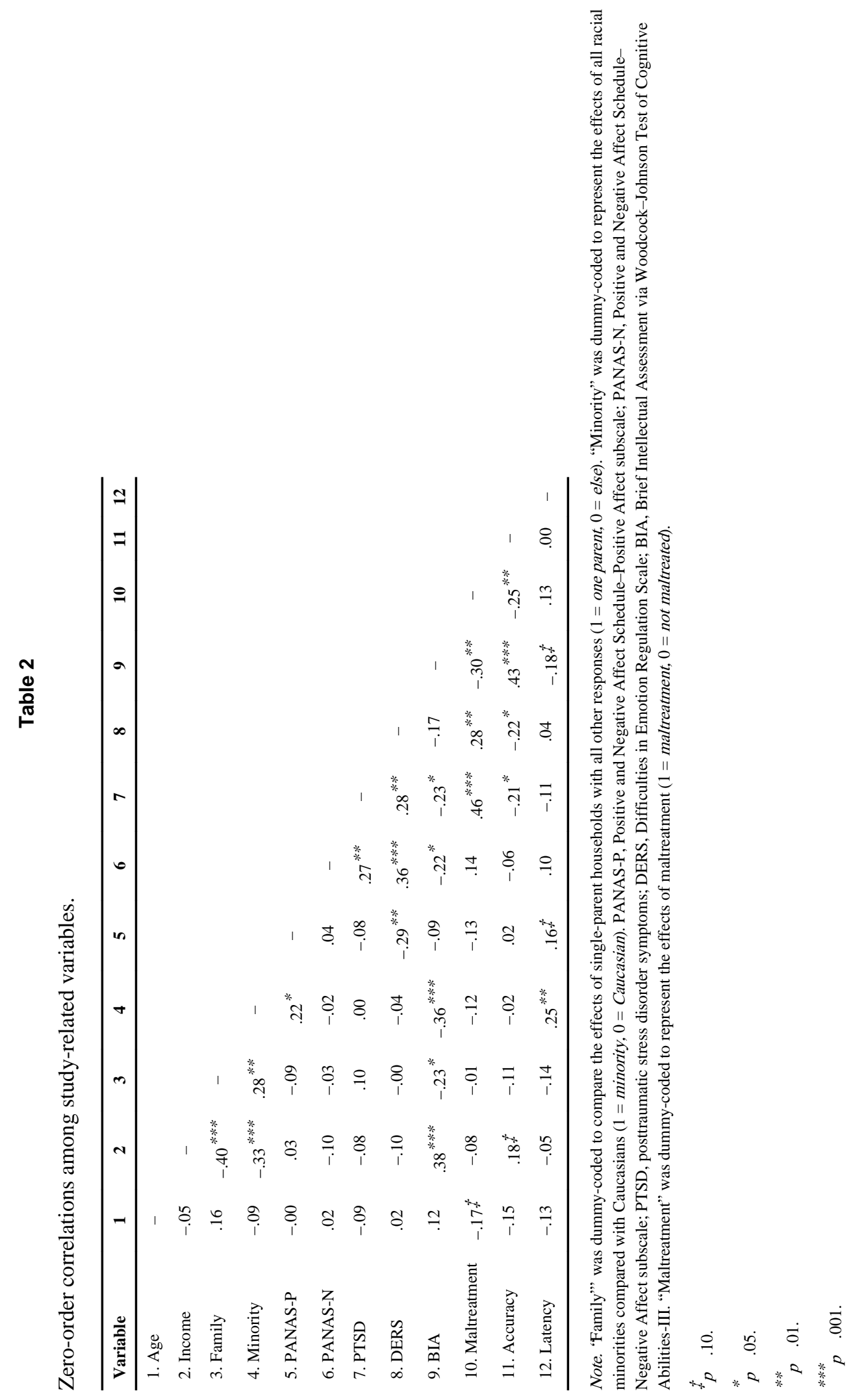




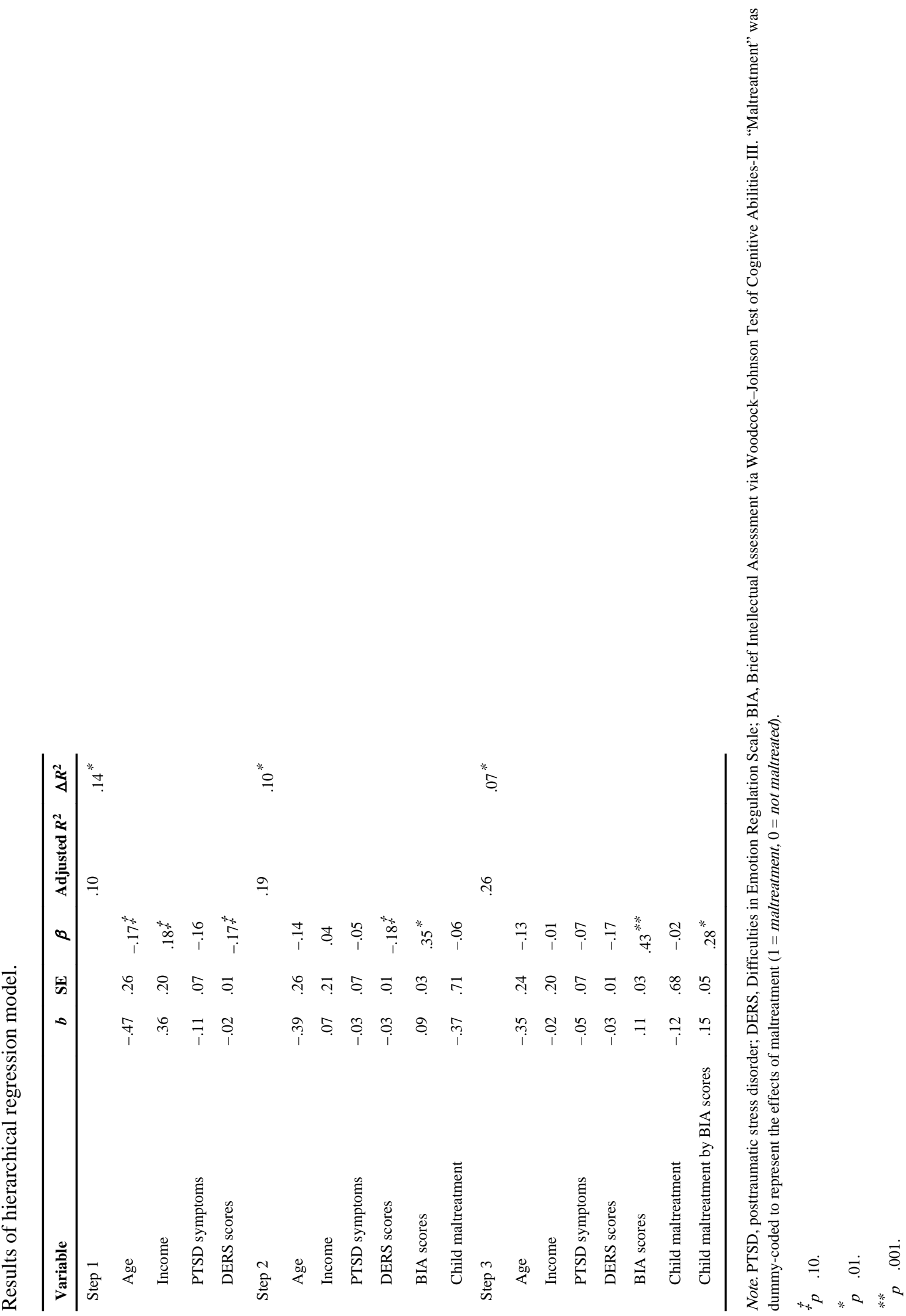

